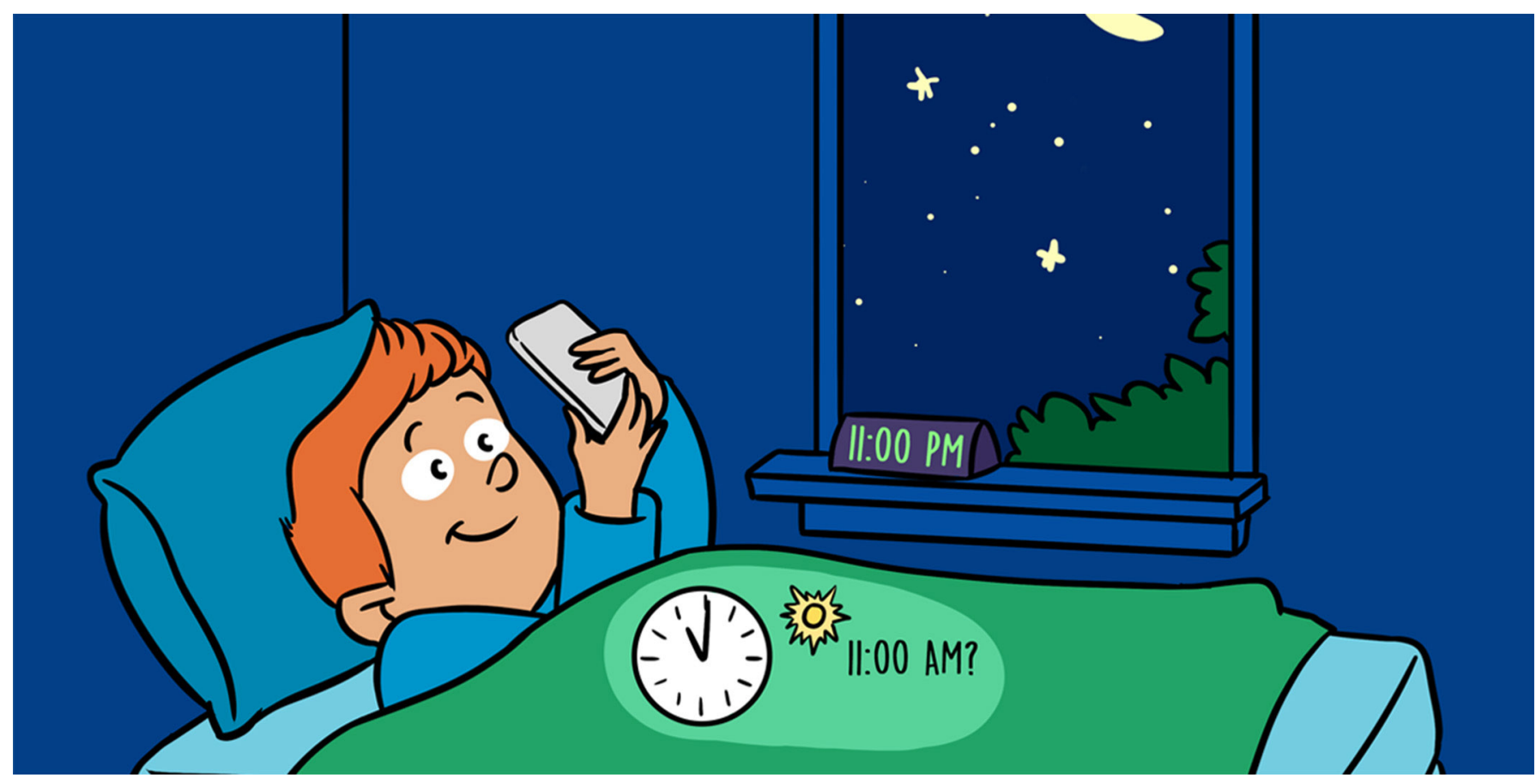

\title{
HOW DO OUR CELLS TELL TIME?
}

\section{Katharine F. Addison ${ }^{1}$ and Julia J. Harris ${ }^{1,2 *}$ \\ ${ }_{1}^{1}$ Neurophysiology, Francis Crick Institute, London, United Kingdom 2 Life Sciences, Imperial College London, London, United Kingdom}

YOUNG REVIEWERS:

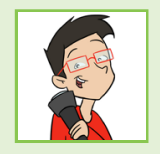

LAURI

AGE: 16

TUOMAS

AGE: 15

\section{BIOLOGICAL CLOCK}

\section{A molecular}

mechanism that keeps track of time within the cells of an organism, and gives rise to circadian rhythms.
Did you know that your cells can tell the time? Every cell in your body has its very own clock. These clocks are unlike any other. There are no cogs or gears. The time is set by the rotation of the Earth, so that our bodies are perfectly aligned with night and day. While you may not even be aware of their existence, these clocks control many aspects your life. From when you eat and sleep to your ability to concentrate or run fast, the clocks command all. How do these clocks work and how do they tell the time? What happens to our clocks if we watch TV late at night or fly to the other side of the world? This article examines these questions and explains the scientific discoveries that have helped us to understand the answers.

\section{THE BIOLOGICAL CLOCK}

Our cells learned to tell the time before we did. Every cell in our bodies has its very own clock. Unlike the clocks we are used to, the clocks in our cells have no cogs or gears: they are biological. Our biological clocks 


\section{CIRCADIAN RHYTHM}

Any process in an organism that falls into a 24-h rhythm or cycle.

Box 1

Clock genes and the 2017 Nobel Prize.

\section{PERIOD}

The clock gene that codes for the PER protein.

\section{PER}

A protein involved in setting the circadian rhythm: its levels fluctuate in a regular 24-h cycle.

\section{CYTOPLASM}

The jelly-like substance that gives cells their shape.

keep near perfect time with the 24-h cycle of light and dark on Earth. We call this regular daily cycle the circadian rhythm. The word circadian comes from the Latin circa and dies, meaning "around the day." The circadian rhythm aligns our sleep-wake cycle with the light-dark cycle, so that we feel awake during the day and sleepy at night. It gets the gut ready for food digestion during the day but helps us not to feel hungry when we are asleep at night. It determines when we are most alert (mid-morning), when we are most coordinated (early afternoon) and when we have the most muscle strength (late afternoon). Body temperature and blood pressure also increase and decrease throughout the day. Even our immune systems operate on a 24-h schedule, guided by the circadian rhythm.

Circadian rhythms are not unique to humans: almost every organism on Earth has a biological clock. Plants' clocks prompt their leaves to open during the day and close at night. The clocks of nocturnal animals promote activity at night and sleep during the day. By tracking changes in the length of daylight, plants and animals can follow a yearly rhythm as well as a daily one. From flowers blooming in spring to Monarch butterflies migrating before winter, biological clocks are responsible. Except for in the darkest caves and deepest oceans, where sunlight never reaches, all life on our planet is in sync with the rotation of the Earth.

\section{THE COGS OF THE CLOCK}

Our biological clocks are unlike any clock that we could read. The cogs of the clocks are proteins. Clock proteins are produced and broken down in a cycle that lasts $24 \mathrm{~h}$ (see Box 1 for detailed explanation). This cycle ticks away in every cell in the body, meaning that each cell has its own clock. But how do all of these separate tiny clocks stay in

In 1971, Seymour Benzer and Ronald Konopka found a strange fruit fly that had an altered circadian rhythm. The researchers discovered that this fly had a mutation in one gene, which they named period [1]. This was the first evidence that our clocks are controlled by our genes. On this day, the first "clock gene" was discovered. So how does period make our clocks tick? Scientists found that period makes a protein called PER. PER is made and destroyed in a continuous 24-h cycle (Figure 2). During the night, period gives instructions for PER to be made. As PER builds up in the cell's cytoplasm, it links up with another protein, TIM. When linked to TIM, PER can enter the cell's nucleus-where the period gene lives. Here, PER tells period to stop making more PER. During the day, PER is slowly destroyed. As night approaches, the amount of PER in the cell is so low that the whole cycle begins again, and a fresh batch of PER is made. The discovery of this cycle was so monumental that 2017's Nobel Prize went to the scientists who made it: Jeffrey C. Hall, Michael Rosbash, and Michael W. Young [2]. 


\section{SCN}

Suprachiasmatic nucleus, which is the controls and

synchronizes the whole body's circadian rhythm.

\section{Figure 1}

Aligning our clocks to sunlight. Sunlight is detected by special light-detecting cells, called ipRGCs, at the back of the eye. The ipRGCs send signals to the SCN in the brain.

These signals are the clocks within every cell in the body, so that they are synchronized with the light-dark cycle. part of the brain that processed to coordinate

time with each other? They are coordinated by a central, grandfather clock in the brain, which is called the suprachiasmatic nucleus (SCN for short). The SCN synchronizes all of our cellular clocks with the Earth's rotation. How does it perform this tricky task? Using sunlight! (Figure 1).

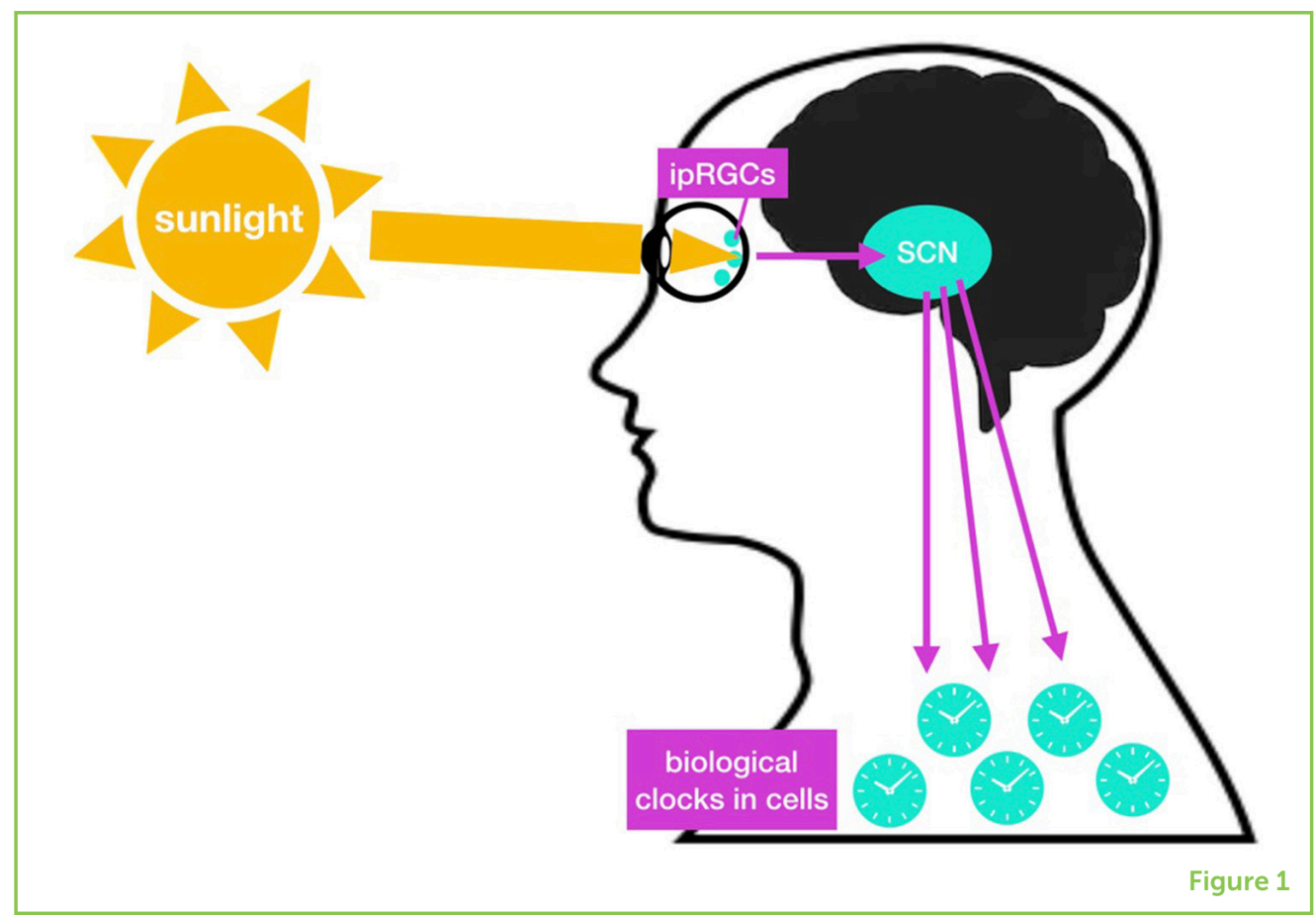

\section{Figure 2}

Cogs of the biological clock. The level of PER protein follows a $24-\mathrm{h}$ cycle, increasing at night and decreasing during the day. (1) The PER protein is produced from the period gene at night. (2) In the cytoplasm, the PER protein pairs with the TIM protein, allowing it to enter the nucleus. (3) When inside the nucleus, PER inhibits its own production. When the level of PER falls below a certain amount, the production of PER increases again. The whole cycle takes $24 \mathrm{~h}$

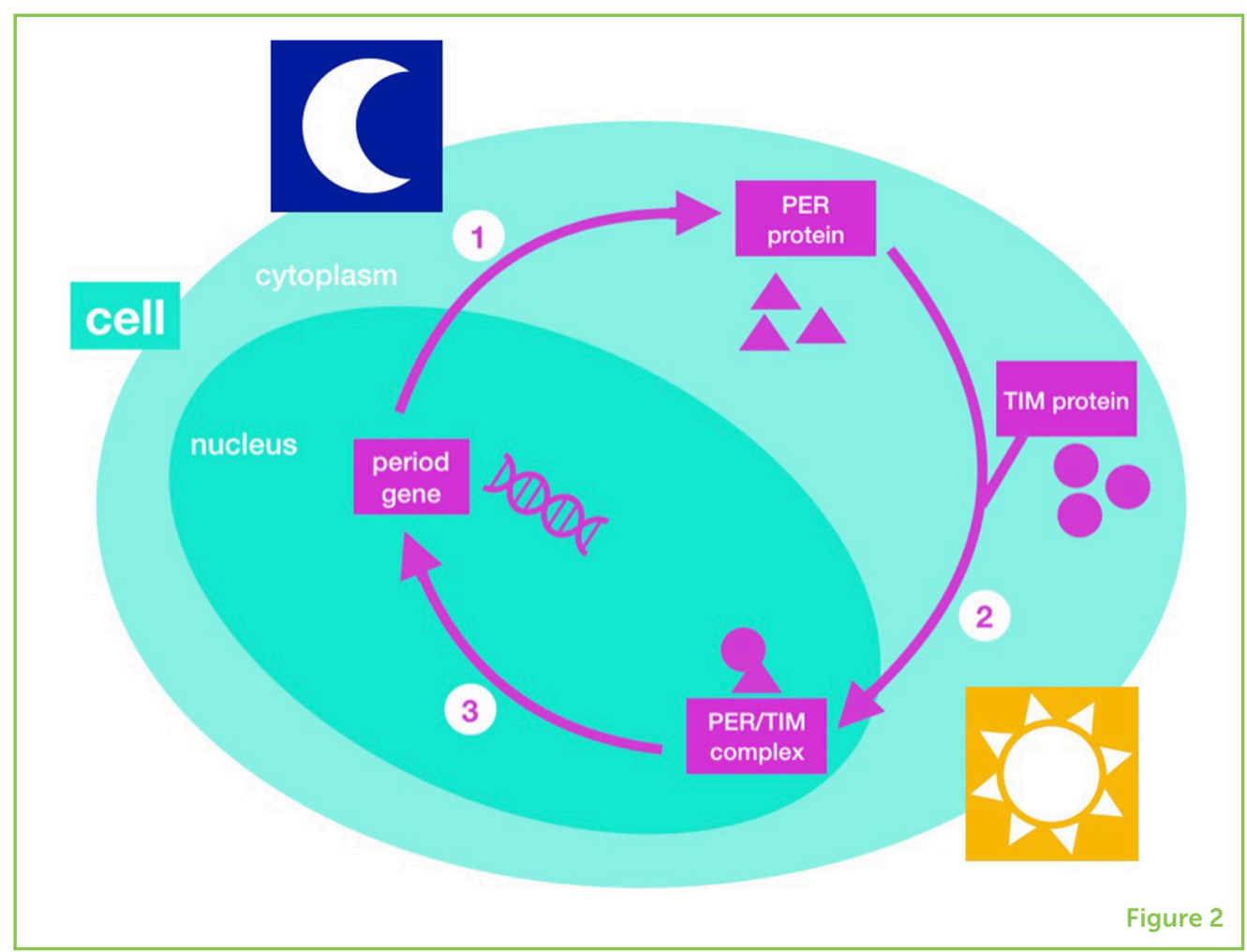


ipRGC

Intrinsic photosensitive retinal ganglion cell, which is a special cell at the back of the eye that detects light and sends this information directly to the SCN.

\section{SETTING THE CLOCKS BY THE LIGHT OF THE SUN}

Just like an old clock, biological clocks must be adjusted to the correct time every day. Light is detected by cells at the back of our eyes, called photoreceptors. Most photoreceptors detect light so that we can see the world around us. But, in 2002, a new type of photoreceptor was discovered that sends signals directly to the SCN [3]. These special photoreceptors are called intrinsic photosensitive retinal ganglion cells, or ipRGCs. If the ipRGCs are working, even blind people can keep their rhythms aligned with the sunlight [4].

Using sunlight, the SCN can adjust the circadian rhythm to gradual changes in daylight hours as we progress through the seasons. But sudden changes in the light-dark cycle can leave us feeling totally out of whack. You may have experienced this yourself: it is called jet lag. Since the invention of airplanes, humans have been able to cross time zones in a matter of hours. An airplane can dump us in bright daylight when our biological clocks are preparing us for sleep. This can leave us feeling drowsy, dizzy and even queasy. Symptoms of jet lag can last for several days, because the SCN takes time to align itself with the new time zone. Now that you know that the SCN uses light to adjust to the time of day, you would not be surprised to hear of the best cure-spend some time in the sun!

\section{ARE WE CONFUSING OUR CLOCKS?}

For over four billion years, the sun was the sole source of light on planet Earth. Only 150 years ago, Thomas Edison invented the light bulb. Since then, our planet has been awash with light. We take our access to light for granted-it is as easy as the flick of a switch. However, should we flick the switch more cautiously? Research suggests that artificial light interferes with our circadian rhythms.

\section{THE PLANET THAT NEVER SLEEPS}

Artificial light means that we can extend daytime activities into the night. It creates a 24-h culture, with restaurants and shops open throughout the night. We can do almost any activity, from reading to driving, at any hour of the day. There are benefits to this. For example, access to healthcare at all times is a lifesaving reality. But what about the doctors and nurses who work through the night? People who work at night must switch their sleep-wake cycles back and forth, and often go days without seeing any natural sunlight. This can cause their biological clocks to get confused, and then all the things that depend on their clocks will also get confused, including sleep. The possible health 
Box 2

The consequences of a confused circadian rhythm and sleep loss.
Proper sleep and a regular circadian rhythm are essential for keeping our bodies and minds functioning well. Which is more important-sleep or the circadian rhythm? This is a tough question to answer, because it is hard to disrupt one without disrupting the other. If you confuse your circadian rhythm (e.g., with jet lag), you will usually also lose some sleep. If you stay awake at night (e.g., because of night-time screen use), then this can disrupt your circadian rhythm. Short disruptions can cause immediate problems, which are usually reversible with a good night of sleep. Chronic sleep loss or circadian confusion can lead to longterm problems for the body and mind.

\section{Short-term sleep loss or jet lag}

- Trouble concentrating

- Increased stress

- Emotional distress

- Feeling unwell

- Memory problems and difficulty learning

- Poor physical performance and coordination

Long-term sleep loss or circadian confusion

- Mood disorders and psychological problems

- Heart and blood pressure issues

- Obesity and diabetes

- Reduced immune response

- Increased risk of cancer

- Worsening of existing medical conditions

consequences of this are listed in Box 2. We should do all that we can to keep our circadian clocks in time.

\section{SCREEN TIME}

There is a newer enemy to our circadian rhythms: LED screens. Phones, computers and TVs have LED screens, which emit a huge amount of blue light. Blue is the color of light that ipRGCs are best at detecting. When this blue light comes from the sun it is a good thing-our brains get the signal from ipRGCs, "it is daytime, stay awake." The SCN responds by inhibiting the production of a hormone that makes us sleepy, called melatonin. When the sun sets, there is no more natural blue light around, and so melatonin is produced, and we become sleepy (Figure 3 ).

Now imagine what happens if you turn on an LED screen after dark. Blue light will be detected by your ipRGCs, which cannot tell that the blue light is not from the sun. So, your brain gets the same signal, "it is daytime, stay awake." The SCN tells the body to produce less melatonin and the level of melatonin falls [5]. With little melatonin around, it can be very difficult to fall asleep, even at bedtime. To avoid confusing our circadian clocks, we should try not to use electronic devices after dark; it may even be best to put them in a different room for the night. This may seem drastic, but just one night of sleep loss and circadian confusion can have serious effects on the body and mind (Box 2). 
Figure 3

Effect of light on the sleepy hormone. Melatonin is a hormone that makes us feel sleepy. (A) Sunshine stops new melatonin being made (in picture, tap is OFF). But melatonin is always being broken down (in picture, dripping drain) So, in the daytime, the level of melatonin in the body is low, and we do not feel sleepy. (B) Darkness triggers the production of melatonin (in picture, tap is ON). So, the level of melatonin rises and we become sleepy when it is time for bed. (C) Using LED screens after dark interferes with this rhythm by stopping melatonin production, just like the sun does. This stops us from feeling sleepy even though our bodies are ready for bed.

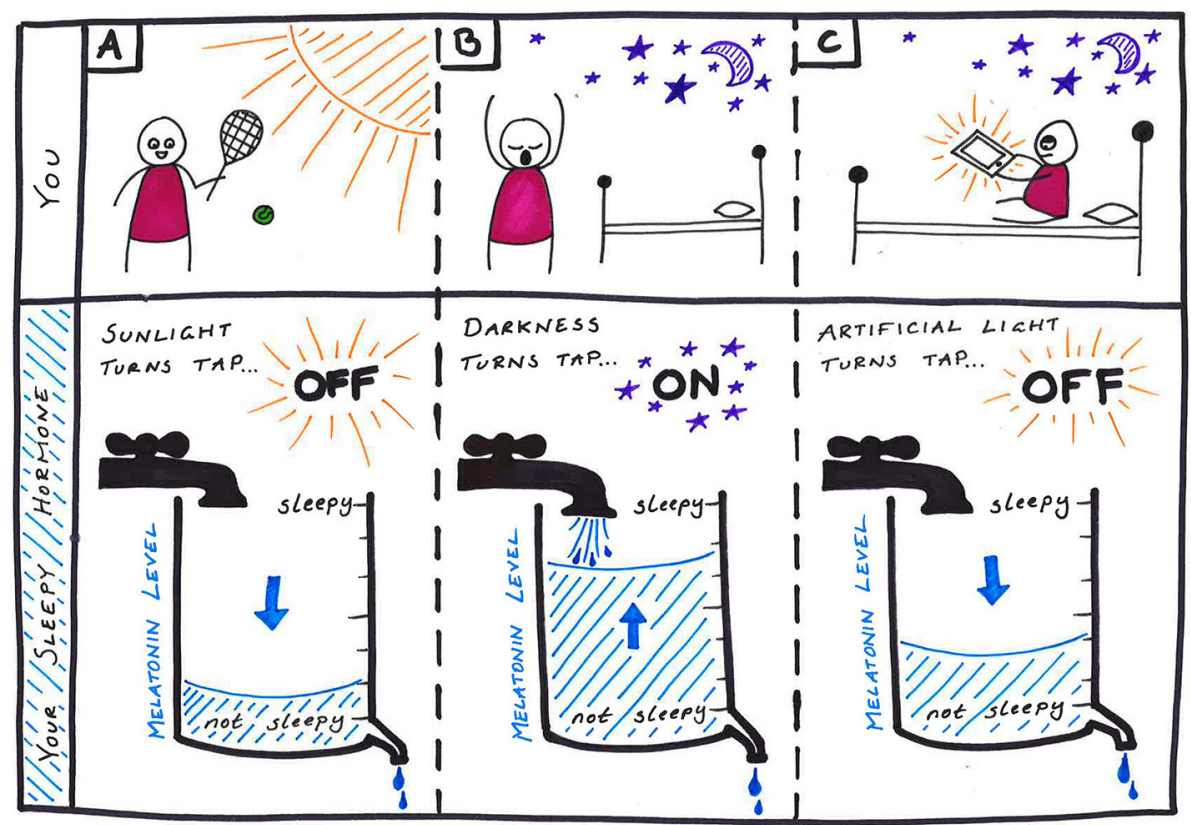

Figure 3

\section{SUMMARY}

Without us being able to see or read them, tiny clocks within our bodies keep time with the Earth's rotation. These clocks control the behavior of nearly all organisms on the planet, ensuring that we all do the right things at the right time of day. The cogs of these clocks are genes and proteins, cycling in a 24-h rhythm within every cell. These cellular clocks are all coordinated by a central, grandfather clock in the brain. Sunlight is used to keep the internal rhythm in sync with the world around us. Normally, this whole process happens so seamlessly that we are not even aware of our biological clocks. But when our clocks are out of sync, we feel the effects. Our modern world, with 24-h light, LED screens, and airplane travel, can confuse our biological clocks. We should do what we can to help our clocks to keep time.

\section{AUTHOR CONTRIBUTIONS}

KFA and $\mathrm{JJH}$ researched and wrote the article together.

\section{ACKNOWLEDGMENTS}

We would like to thank Isabell Whitely for her careful review of the article and Carles Bosch for his insightful comments on the figures. KA would also like to thank the Pathological Society for funding her placement with $\mathrm{JH}$. 


\section{REFERENCES}

1. Konopka, R. J., and Benzer, S. 1971. Clock Mutants of Drosophila melanogaster. Proc. Natl. Acad. Sci. U.S.A. 68:2112-6. doi: 10.1073/pnas.68.9.2112

2. Nobel Prize. The 2017 Nobel Prize in Physiology and Medicine-Press Release. Available online at: https://www.nobelprize.org/nobel_prizes/medicine/ laureates/2017/press.html (accessed July 14, 2018).

3. Berson, D. M. 2003. Strange vision: ganglion cells as circadian photoreceptors. Trends Neurosci. 26:314-20. doi: 10.1016/S0166-2236(03)00130-9

4. Czeisler C. A., Shanahan T. L., Klerman E. B., Martens H., Brotman D. J., Emens J. S. et al. 1995. Suppression of melatonin secretion in some blind patients by exposure to bright light. N. Engl. J. Med. 332:6-11. doi: 10.1056/NEJM199501053320102

5. Pilorz, V., Tam, S. K. E., Hughes, S., Pothecary, C. A., Jagannath A., Hankins M. W. et al. 2016. Melanopsin regulates both sleep-promoting and arousalpromoting responses to light. PLOS Biol. 14:e1002482. doi: 10.1371/journal.pbio.1002482

SUBMITTED: 25 July 2018; ACCEPTED: 14 January 2019; PUBLISHED ONLINE: 05 February 2019.

EDITED BY: Silvia A. Bunge, University of California, Berkeley, United States

CITATION: Addison KF and Harris JJ (2019) How Do Our Cells Tell Time? Front. Young Minds 7:5. doi: 10.3389/frym.2019.00005

CONFLICT OF INTEREST STATEMENT: The authors declare that the research was conducted in the absence of any commercial or financial relationships that could be construed as a potential conflict of interest.

COPYRIGHT () 2019 Addison and Harris. This is an open-access article distributed under the terms of the Creative Commons Attribution License (CC BY). The use, distribution or reproduction in other forums is permitted, provided the original author(s) and the copyright owner(s) are credited and that the original publication in this journal is cited, in accordance with accepted academic practice. No use, distribution or reproduction is permitted which does not comply with these terms.

\section{YOUNG REVIEWERS}

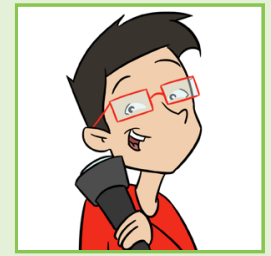

\section{LAURI, AGE: 16}

I live in Finland near to the sea. Music and sports are my hobbies. 

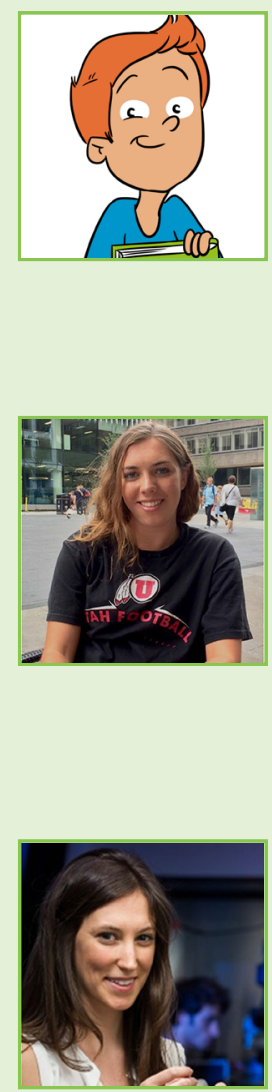

TUOMAS, AGE: 15

I live in Finland.

\section{AUTHORS}

\section{KATHARINE F. ADDISON}

I am entering the second year of my undergraduate degree at the University of Cambridge. I am fascinated by the workings of the brain. This summer, I am pursuing my interests in the Neurophysiology Department at the Francis Crick Institute in London. I hope to specialize in Neuroscience for my degree and continue my studies to Ph.D. level. I am particularly interested in the clinical applications of the science, such as treatments for Alzheimer's disease and treatments for sleep disorders.

\section{JULIA JADE HARRIS}

I am interested in how the brain has evolved so that it can use very little energy to do complicated tasks, and whether sleep is important for the brain to stay energy efficient while also learning new things. To investigate these topics, I measure the brain activity of mice while they learn tasks and while they sleep. I carry out my research between Imperial College London and the Francis Crick Institute. I received my undergraduate degree from the University of Oxford and did my Ph.D. at UCL. * julia.harris@crick.ac.uk 